\title{
Dynamic Substance Flow Analysis as a Valuable Risk Evaluation Tool - A Case Study for Brominated Flame Retardants as an Example of Potential Endocrine Disrupters
}

\author{
Leo S. Morf ${ }^{\star a}$, Andreas M. Buser ${ }^{\mathrm{a}}$, Ruedi Taverna ${ }^{\mathrm{a}}$, Hans-Peter Bader ${ }^{\mathrm{b}}$, and Ruth Scheidegger ${ }^{\mathrm{b}}$
}

\begin{abstract}
Most studies of potentially hazardous substances focus on aspects of their occurrence and fate in the environment (monitoring and modelling studies) to estimate the environmental impact and the potential exposure of humans. In order to evaluate emission sources, to recognise environmental impacts at an early stage, and to take efficient legislative or technical measures, it is essential to know their behaviour in the anthroposphere as a function of time. So far, only very few investigations of this type exist for chemicals. In regular risk assessments, only rather limited knowledge is available concerning the behaviour of chemicals in the anthroposphere (production data, substance quantities in products, recycling rates, emissions occurring during use, etc.) or their lifecycle, and no information at all about their behaviour as a function of time. For this reason, it is these aspects that were investigated in a case study within the framework of the national research programme NRP50 for selected brominated flame retardants with endocrine-disrupting potential (pentabromodiphenyl ether, hexabromocyclododecane) or the potential to degrade to such substances (decabromodiphenyl ether). A dynamic substance flow analysis (SFA) model was performed for Switzerland for the time period 1980-2020. In this review paper (a) we present a summary of typical results (system overview, consumption trends/application patterns, anthropogenic stocks and their changes, emission trends including major sources and environmental fate), (b) we summarize the effectiveness of recent risk-reduction measures in Switzerland and (c) we indicate serious remaining data gaps and recommend further important measures for risk reduction. For the future, we suggest improving the knowledge of the lifecycle of chemicals such as brominated flame retardants by applying SFA as a suitable tool to weight the effect of substance flows with respect to environmental emissions, and to serve as the basis for planning actions and measures to reduce such emissions. This is in line with one major conclusion of the NRP50 consensus platform 'Brominated Flame Retardants'.
\end{abstract}

Keywords: Anthroposphere - Brominated flame retardants · Dynamic substance flow analysis · Emission . Lifecycle of chemicals

${ }^{*}$ Correspondence: $\mathrm{Dr}$ L S. Morf

Tel.: +41443112728

E-mail: morf@geopartner.ch

aGEO Partner AG

Baumackerstrasse 24

$\mathrm{CH}-8050$ Zürich

www.geopartner.ch

bSwiss Federal Institute of Aquatic Science

and Technology

Überlandstrasse 133

$\mathrm{CH}-8600$ Dübendorf

\section{Introduction}

\section{Brominated Flame Retardants} (BFRs) - High Production Volume Chemicals with Endocrine Potential

BFRs are important synthetic additives which are used to reduce the flammability of plastic products, enabling them to fulfil the testing requirements of electrotechnology, vehicle construction and building technology. Flame retardants are incorporated into plastics (polymers) or applied as coatings to textile fibres. More than 75 different BFRs are available commercially. ${ }^{[1]}$ Five of the most important BFRs on the market are tetrabromobisphenol A (TBBPA), three technical mixtures of polybrominated diphenyl ethers (PBDEs), which are known as decabromodiphenyl ether (decaBDE), octabromodiphenyl ether (octaBDE) and pentabromodiphenyl ether (pentaBDE), and hexabromocyclododecane (HBCD). The worldwide market demand in metric tonnes in 2001 was reported to be 119,700 for TBBPA, 67,300 for PBDEs (56,100 for decaBDE, 7,500 for pentaBDE, and 3,790 for octaBDE) and 16,700 for HBCD. [2]

Despite their benefits, unfortunately many representatives of BFRs qualify as persistent, bioaccumulative and toxic substances (PBT). The properties of some BFRs are typical for persistent organic pollutants (POP), and certain BFRs are suspected to cause adverse health effects. ${ }^{[3]}$ Due to these facts, there has for many years been a strong and increasing research ac- 
tivity and public awareness campaign concerning these products.

The endocrine-disrupting properties of $\boldsymbol{B F R \boldsymbol { s }}$ was reviewed recently by Legler and Brouwer. ${ }^{[4]}$ According to their review, substantial evidence exists to indicate that BFRs are potential endocrine disruptors, and their potency to disrupt thyroid hormone-mediated pathways has been demonstrated in both in vitro and in vivo studies. The EU project FIRE, 'Risk assessment of BFRs as suspected endocrine disrupters for human and wildlife health' (http://www. rivm.nl/fire), has focussed a large research effort on this topic. BFRs are also investigated in detail in the national research programme NRP50, 'Endocrine Disrupters Relevance to Humans, Animals and Ecosystems'. As part of this research program, representatives of the NRP, the authorities and the producing and applying industries have prepared recommendations to avoid the negative impact of endocrine disruptors in a consensus platform. According to current knowledge, with regard to endocrine activity of BFRs, the platform concluded: "Several brominated flame retardants are chemicals with endocrine activity. Studies conclude that pentaBDE, banned since 2004, has antiandrogenous and estrogenous effects and causes malfunction of the thyroid hormone system. According to the most recent findings, TBBPA and HBCD are considered potential endocrine disruptors. It is still unclear to what extent newfound knowledge from in vitro and in vivo studies can be applied to humans.' [5]

\section{Common Tools for Risk Characteri- sation and Risk Reduction}

As common tools for risk characterisation for chemicals, risk assessments (RAs), as defined in the Technical Guidance Document on Risk Assessment, ${ }^{[6]}$ are applied. There are to date only rather limited RAs of substances available compared to the high number of commercial chemical substances produced both in the past and at present. In current RAs, especially for the calculation of predicted environmental concentrations (PEC) in the 'environmental exposure assessment', the available field data set is usually limited. Often only highly aggregated data are available (e.g. world production volume). Emission factors and other factors have to be estimated, and field data (including concentrations in products, waste and environmental compartments) are very scarce or not available at all. It is quite normal that major data gaps also exist regarding losses during the service life of products or in the end-of-life phase (e.g. leachates from landfills, emissions during recycling activities). The behaviour of concentrations, flows and stocks as a function of time are scarcely investigated at all. For BFRs the European Commission finalised the RA of pentaBDE in 2000. [7] The RA of octaBDE was finished in 2002. ${ }^{[8]}$ In the meantime these two substances have been banned in Europe. In May 2004 the Competent Authorities of the EU officially closed the RA of decaBDE without any restrictions due to a lack of risks identified for the use of this substance. ${ }^{[9]}$ The RAs of the HBCD and TBBPA have not yet been completed. In the event that a policy decision is made to reduce the risk of certain chemicals according to the outcome of the RAs, studies to define risk-reduction strategies and measures are applied (such as for decaBDE in Europe). There are currently industrial initiatives such as the Voluntary Emission Control Action Programme (VECAP) set up by the Bromine Science and Environmental Forum (BSEF).

\section{The Dynamic Anthropogenic Metabolism of Chemicals}

To characterise risks and to define effective risk-reduction strategies for chemicals, it is essential to gain knowledge about their behaviour in the anthroposphere by applying substance flow analysis (SFA). This in cludes the evaluation of sources, substance flows and pathways, stocks in private households, industry and waste management and residual fluxes into the environment, as well as the final sinks of the substances concerned. Additionally, information abou the behaviour of the system as a function of time (production volume changes, emission factor reductions due to technology improvement, changes in end-of-life options, stock management, etc.) is important to allow early recognition of potential future problems. Normally, this information is not yet available in adequately detailed form in common RAs for chemical substances. Worldwide, only very few SFAs have to date been performed for chemical substances. Similarly, only very few studies have investigated the behaviour of substances in the anthroposphere as a function of time $\left(\right.$ e.g..$\left.^{[10-13]}\right)$. These statements are also true for the BFRs discussed in this paper. Limited research work has focussed on the most important applications areas, flows and stocks in the waste management sector, and also on releases from use and disposal into the environment. ${ }^{[14-17]}$ However, none of these studies have investigated the time-dependence of the behaviour in the anthroposphere.

The project discussed in this review was therefore initiated within the framework of NRP50, and aims to determine the behaviour of the substance transfer of selected BFRs within and from the anthroposphere (technosphere) to the environment (ecosphere) in a case study for Switzerland. The results were intended for a comparison to the results of other NRP50 projects dealing with measurements in different environmental compartments as a basis to investigate causality and to evaluate the effectiveness of recent measures, or to define necessary additional risk-reduction procedures.

\section{Material and Methods}

\section{The System}

The spatial system boundary is the political border of Switzerland and the time period is 1980-2020. The substances decaBDE, HBCD and BDE-47 were selected. BDE-47 was selected because it is the most environmentally relevant congener of the commercial pentaBDE mixture with endocrine effects. It was banned in Europe in 2004, but is still used in other regions, and remains available both in stocks and through disposal. The selection criterion for HBCD was that it is a potential endocrine substance, which is used increasingly in applications with long lifetimes. DecaBDE was selected due to the fact that there is evidence for its degradation to lower brominated BFRs such as pentaBDE.

In order to take into account their different behaviour in the anthroposphere, the use of the selected BFRs was divided into four application areas $(E \& E$ (electrical and electronic equipment), transport, textiles/furniture and construction). Fig. 1 illustrates the system established for the application areas E\&E, transport and textiles/ furniture. The system for the construction application area (not shown here) allows a more detailed investigation of the use process.

\section{The Model}

In order to investigate the dynamic behaviour in the anthroposphere, and to simulate future emissions from the anthroposphere to the environment, a dynamic SFA model was established. A dynamical model is crucial for two reasons:

i) the input into the use phase may vary rapidly over time;

ii) the residence times of brominated flame retardants in the use phase are on the order of $10-50$ years.

These large residence times induce large delays between the input and output of the use phase, which cannot be described by a stationary model. The dynamic model is based on the method of mathematical material flow analysis, which was extended from material flow analysis by Baccini and Bader ${ }^{[18]}$ for the dynamic case. It is based on a system of coupled integro-differential equations with (time-dependent) parameter functions using the SIMBOX ${ }^{\circledR}$ software. Very briefly, the model approach can be described as follows:

i) the substances enter the use phase according to a given, time-dependent consumption pattern; 


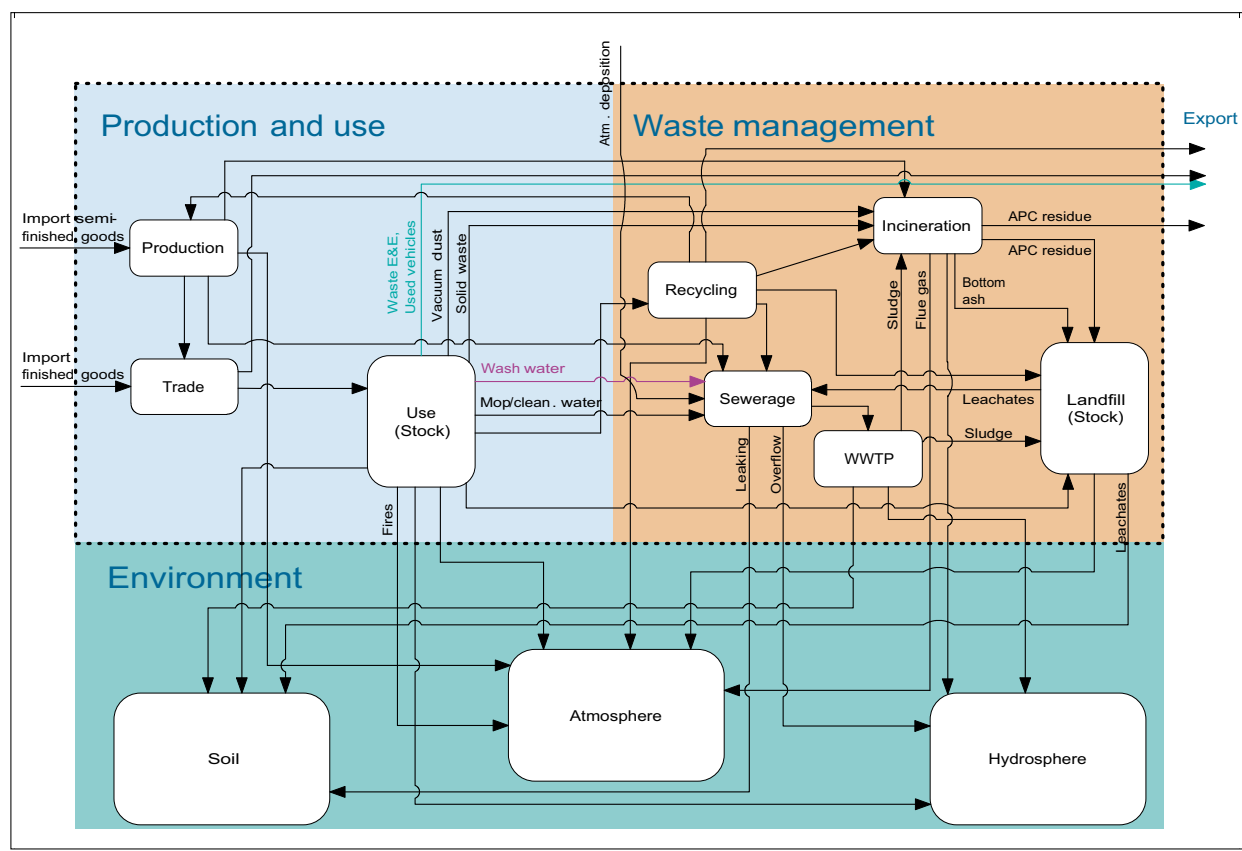

Fig. 1. System definition for the application areas $E \& E$, transport and textiles/furniture for the selected BFRs decaBDE, HBCD and BDE-47 (APC residue = air pollution control residue)

ii) during use, they are emitted according to determined emission factors;

iii) the remainder is distributed after its residence time in the use phase to the waste or recycling processes according to time-dependent transfer coefficients;

iv) finally, the waste processes are described by time-dependent transfer coefficients, also related to all or part of the input.

\section{Data Acquisition and Uncertainty}

Time series for the parameter functions (consumption, residence times, transfer coefficients and emission factors) were estimated based on our own studies, ${ }^{[16,19]}$ broad literature data, multiple contacts with research groups, organisations, authorities and industry, and our own calculations and assumptions.

To evaluate consumption and application patterns, product use-figure data and BFR contents were investigated in detail. Emission factors for the production, use and end-of-life phases were applied to the model. Emission flows from the production and end-of-life phases depend heavily on production and waste management technologies, where the state of the art progresses continuously. New production techniques, more efficient air-pollution-control systems and similar advances influence emission factors strongly. These changes were considered in the model according to the available literature data and to our own estimates. The time-dependent factors applied in the model differ for the different time periods, what has a significant effect on emission levels over the time period investigated. In addition, various alternatives for the reuse and disposal of end-of-life products, such as recycling, incineration and landfilling, have a significant impact on the level of emissions. Waste management strategies are also time-dependent and as such were considered on the same level in the model. This information, together with emission factors for each disposal alternative depending on state of current technology, is necessary for an accurate determination of emissions to the environment.

Uncertainty in the consumption figures, transfer coefficients and emission factors was evaluated or estimated according to available data. The model allowed us to simulate the uncertainty of the flows in the anthroposphere and into the environment. These results, and a full discussion regarding the uncertainty, are beyond the scope of the current paper, but are presented in refs. [20] and [21].

\section{Modelling the Environment}

The modelling of the Swiss environment was carried out in cooperation with other NRP50 projects, and with other research groups focussing on the investigation of the Swiss environment, including FLEET flows for individual environmental compartments as well as degradation losses), FLARE (levels in the environment including water, sediment and animals) and ENDAIR (occurrence and fate of BFRs in the air). This has allowed us to benefit from the high synergy potential within the NFP50 research framework, and to include the latest research results for Switzerland.

Details regarding the environmental fate model, including parameter selection, uncertainty estimation and predicted environmental concentrations, may be found in ref. [21]. (determination of input and output mass

\section{Results and Discussion}

In this review article we present selected key results for the two BFRs pentaBDE (BDE-47) as a chemical which is no longer used in Switzerland, and HBCD as a chemical which has a rather different (increasing) consumption pattern. As noted above, full results from the dynamic substance flow analysis for the selected BFRs are presented in refs. [20] and [21].

\section{Consumption and Application Patterns}

In addition to the simulation results, such as stock changes and emission trends, the major results of the project are the consumption and application patterns established in the data-acquisition phase.

In Fig. 2, the consumption data for Switzerland from 1980 to date, and extrapolated to 2020, are shown for pentaBDE and HBCD. These figures are the result of extensive investigations, and serve as input data for the dynamic model. Fig. 2a shows the consumption time pattern of a typical chemical substance phased out due to risk considerations (pentaBDE). The consumption of pentaBDE reached a maximum of 14 tonnes/year in Switzerland in the beginning of the 1990s. Only a negligible consumption of pentaBDE was assumed from 2006 onwards. Even though the use of pentaBDE persists in some countries, including China, its import in products to Switzerland was estimated to be very small. The largest component of its consumption was estimated to be its use in rigid polyurethane (PUR) foam in the construction sector. Flexible PUR foam in vehicles and furniture, PVC sheeting and printed circuit boards are other applications for pentaBDE. The data series for Switzerland were compared to other data sources. The data series for Europe by Prevedouros et al. ${ }^{[22]}$ are in good agreement. The differences, calculated on a per capita basis from European industry demand data supplied by the Bromine Science and Environmental Forum (BSEF) and the European Chemical Industry Council (CEFIC), are explained primarily by the different fire regulations standards in European countries.

By contrast, HBCD represents a typical substance with a steadily increasing consumption rate, which in fact increases over the entire time period investigated (Fig. 2b). The consumption reached 100 tonnes/year in the mid-nineties, and since then has almost doubled (180 tonnes/year) up to the present. The construction materials EPS and XPS make up by far the most important component of HBCD consumption ( $84 \%$ in the present year). The application areas transport $(9 \%)$, textiles/furniture and E\&E (3.5\% each) are less important. According to available information, a future increase in use was assumed for construc- 


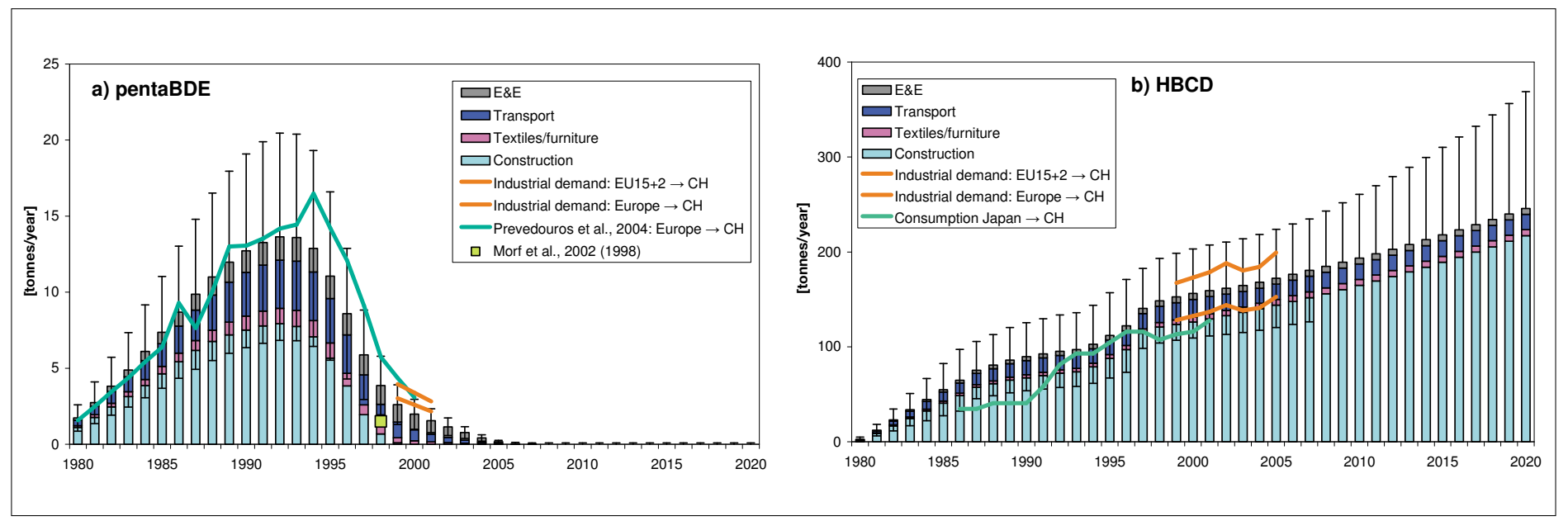

Fig. 2. Estimated consumption and application patterns of (a) pentaBDE and (b) HBCD in Switzerland, including their estimated uncertainty (no lower boundary after 2007 due to the possibility of a ban). The European industrial demand data (source: BSEF and CEFIC) and estimates by Prevedouros et al.[22] for Europe are compared on a per capita basis. Also shown is the result of an earlier SFA study for Switzerland at the end of the 1990s. ${ }^{[16]}$

tion materials. The per capita consumption in Switzerland is comparable to data on European industrial consumption provided by the BSEF and CEFIC. As Switzerland has stringent fire regulations for buildings, it is reasonable to assume that the per capita use of HBCD is slightly higher than the European average (lower orange line in Fig. 2b). While HBCD consumption in Asia is in general considerably lower than in Europe, Japan uses similar amounts on a per capita basis as do Switzerland and Europe.

\section{An Overview of Substance Flows and Stocks in $\mathbf{2 0 0 0}$}

Traditional SFAs were carried out for a selected year or time span $\left(e . g .{ }^{[15,16]}\right)$. This kind of SFA yields an overview of flows and stocks in the system investigated. This analysis is useful to identify key flows and processes in order to determine sources posing actual risks at the time investigated. As noted above, such analyses are not suitable for real dynamic systems with time-dependent inputs and large residence times. In particular, dynamical models are necessary to simulate the effect of possible measures such as bans on the import or use of certain substances.

Fig. 3 shows an example of the dynamic model results for Switzerland in 2000 for pentaBDE (BDE-47). The example is for the application area $E \& E$ only. Fig. 3 shows a total import for these applications of $770 \mathrm{~kg} /$ year BDE-47 (corresponding to 1.9 tonnes/year pentaBDE) at this time. We note that $45 \%$ of the imported amount is exported in the same year, while $410 \mathrm{~kg}$ / year of BDE-47 is used in many different $E \& E$ appliances in Switzerland, mainly in printed circuit boards. In the same year, the BDE-47 flow from the use phase to the waste management system is approximately $520 \mathrm{~kg}$. Only a small part of this output is related directly to the input of the same year. The stock in the use phase (con- sumer products and industrial appliances) decreases by about $120 \mathrm{~kg}$ during this year. Some $65 \%$ of the pentaBDE in disposedof articles is incinerated, $30 \%$ is exported and $5 \%$ is landfilled. There is no recycling of the substance itself, even though a large fraction of the end-of-life products is recycled. The total stock in landfills related to this application area is almost $800 \mathrm{~kg}$, and still slightly increasing ( $+2 \%$ in 2000$)$. During production, use and disposal in the E\&E sector, approximately $0.3 \mathrm{~kg} /$ year of BDE-47 (approx. $0.7 \mathrm{~kg} /$ year pentaBDE) was emitted to the environment. This corresponds to $0.14 \%$ of the consumed penta BDE quantity for this application area. About half of the total was emitted into the atmosphere, one third into soil and the rest into the hydrosphere.

For 2000, the total pentaBDE consumption for all four application areas was around 2 tonnes (Fig. 2). The $E \& E$ application area accounts for approximately $60 \%$ of the total use at this time. The total flow of BDE-47 from use and production to waste management accounts for 1.7 tonnes/year (corresponding to 4 tonnes/year pentaBDE). This indicates an almost balanced input-output in the use phase for all applications in 2000. The stock of BDE-47 in the use phase was simulated as 55 tonnes (corresponding to 140 tonnes of pentaBDE). Most of this amount is stored in the infrastructure and will be released only in many years, when buildings are renovated or replaced. The total emissions of BDE- 47 were simulated as $2.5 \mathrm{~kg}$. The contribution of emissions from $E \& E$ during the appliance production, use and end-of-life phases for BDE-47 is approximately $0.3 \mathrm{~kg} / \mathrm{year}$, which is a small quantity relative to the sum of the contributions from the other areas (transport: 0.9 $\mathrm{kg} / \mathrm{year}$, textiles/furniture: $0.2 / \mathrm{year}$, construction: $1.1 \mathrm{~kg} / \mathrm{year}$ ).

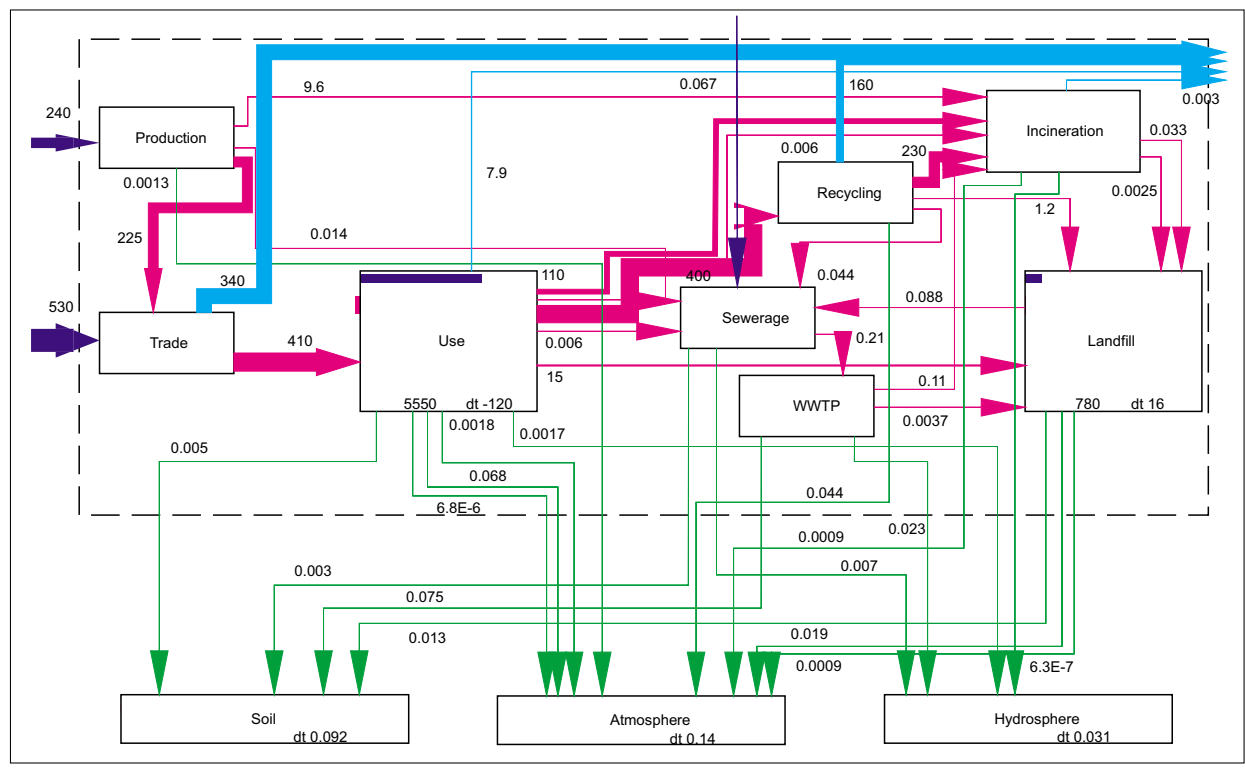

Fig. 3. BDE-47 substance flows (kg/year), stock change rates (kg/year, 'dt' in boxes) and stocks (kg, in boxes) in the anthroposphere in the application area E\&E in Switzerland in the year 2000 


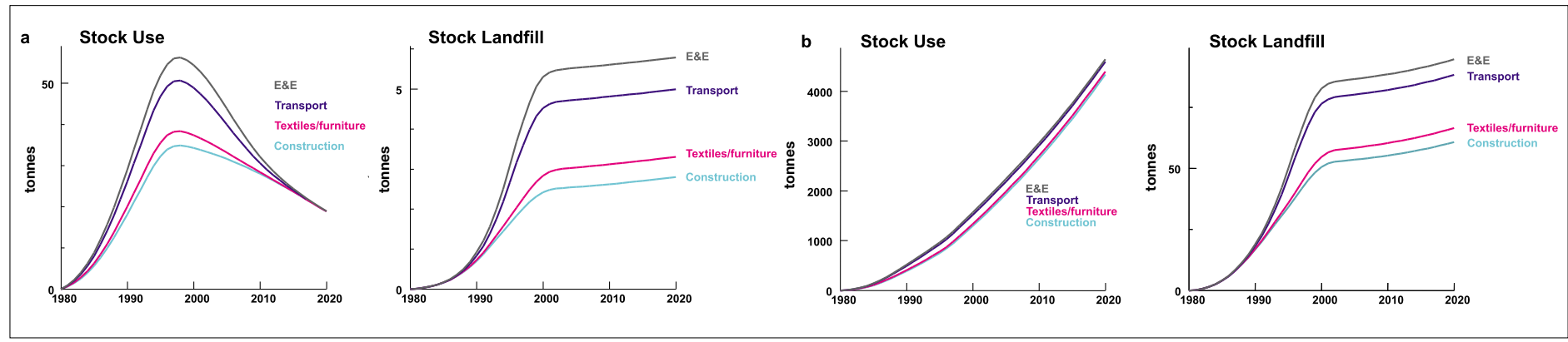

Fig. 4. Stocks of (a) BDE-47 and (b) HBCD in the processes use and landfill as a function of time (cumulative graphs)

The results of the comprehensive dynamic SFA showed some significant differences to the results of an earlier SFA study for Switzerland at the end of the 1990s. ${ }^{[16]}$ These differences are due to the dynamical approach, to a more in-depth analysis regarding production figures and consumption patterns, to the availability of more field data, such as concentrations in products, and to experiments performed to determine the emission factors used in this study.

\section{Anthropogenic Stocks as Potential Future Risks}

Consumption behaviour, residence-time characteristics and also waste management strategies influence the behaviour of the two stock types in the anthroposphere: use phase stock (consumer or industrial products in use, as well as construction materials incorporated in infrastructure) and the stock in waste management (landfills). These stocks are potentially long-term sources of pollutants leaching or volatising to the environment. Information about stocks is therefore essential to estimate past, present and future emissions.

Fig. 4 shows the simulated stock levels as a function of time for pentaBDE (BDE-47), and HBCD. Consumption of pentaBDE (BDE-47) has been decreasing since 1993, and the stock in the use phase started to decrease after a time delay of about five years in 1998. The stock change varies significantly, depending on the residence-time characteristics of the products applied in the different application fields. Applications of pentaBDE in construction materials with very long residence time are responsible for the fact that it takes more than 20 years to observe a $2 / 3$ decrease of the entire stock in the use phase. By 2020, 1/3 of the stock will still remain in buildings and is a potential source for diffuse emissions to the atmosphere and soil. Due to their lower residence time in transport vehicles, textiles and E\&E products, the maximum stocks of these products in the use phase will be reduced within the period from 1998 to 2010 to almost zero. In particular, the decreasing stock of old vehicles including pentaBDE in PUR foams has a significant positive effect regarding emission reduction during the use phase.
In contrast to pentaBDE, HBCD stock in the use phase shows a continuous increase since 1980 and - without any ban - is expected to double in the next 13 years until 2020. As most of the HBCD applications are dedicated to construction materials with a residence time of 50 years or more, measures such as restrictions or a ban on HBCD will have only a highly delayed effect in reducing diffuse emissions from construction materials in buildings. Such effects can only be simulated by dynamic models. Additionally, the increasing HBCD stock seen in Fig. $4 \mathrm{~b}$ indicates possible problems arising in the recycling of construction materials in the future, when buildings of the present period are renovated or destroyed. For other application areas these aspects do not play a relevant role.

Mainly as a consequence of the Swiss waste management strategy of incinerating burnable waste, the stocks in landfills are at a low level compared to the maximum stock built up in the use phase. For pentaBDE it is approximately ten times lower than the maximum stock in use in 1998. For HBCD it is projected to be almost two orders of magnitude lower than at maximum stock level in 2020. Most BFRs which are disposed of are destroyed in efficient municipal waste incinerators. This fact, and the effort to limit and control landfill emissions, are responsible for the fact that long-term landfill emissions in Switzerland are negligible for HBCD and remain at a rather low level for BDE-47 (see below).

\section{Behaviour of Emissions to the Environment as a Function of Time}

As stated in the introduction, one primary aspect of the study was to simulate emissions in the environmental compartments and to relate them to sources in the anthroposphere as a function of time. In Fig. 5 these results are presented for BDE-47 and HBCD during the time period investigated. In addition, for BDE-47, the contributions of the three main source categories production, use and waste management to the total emission flows into the three environmental compartments atmosphere, hydrosphere and soil during the simulated time period are presented in Fig. 5.
As illustrated in Figs. 5 and 6, emissions of BDE-47 are one order of magnitude lower than of HBCD. For BDE-47, there was an increase until the middle of the 1990s, with a peak emission of $2.5 \mathrm{~kg} /$ year. By the end of the investigated period, the emissions were simulated to drop below $1 \mathrm{~kg} /$ year. The largest proportion of the emissions is released to the air, while emissions to water and soil are of lower significance.

Diffuse emissions from BDE-47containing products in the use phase have provided the largest contributions to total emission into the environment. This contribution was $2 / 3$ in the mid-1990s, and was simulated to remain at approximately $50 \%$ in the future. Rigid and flexible PUR foams in construction and in furniture, as well as in vehicles, were simulated to be the major sources for these emissions. Emissions from construction materials will continue for several decades, as the residence time in the use phase is longer compared to the other application areas. Because there is no more consumption of pentaBDE in domestic production processes, emissions are expected to fall to almost zero by the present. Recycling of vehicles and E\&E products was simulated to contribute to a notable extent only during the 1990 s, due to technological improvements since then. The amount emitted from wastewater treatment plants (WWTPs) effluents was calculated to remain approximately constant from the mid-1990s until the end of the period under investigation. Due to its higher volatility and mobility compared to other BFRs, a significant quantity of BDE-47 is simulated to be emitted by landfills to the atmosphere and soil even in 2020. The destruction of installed foams was shown to produce increasing emissions to air and soil. However, these are still small contributions compared to the emissions of HBCD caused by the same process.

Emissions of $\mathrm{HBCD}$, in contrast to BDE-47, have been increasing to date and are projected to continue to do so in future (Fig. 5). The largest component of the emissions is simulated to be into the atmosphere. These emissions are simulated to be as high as $50 \mathrm{~kg} /$ year in 2020 , while emissions to 

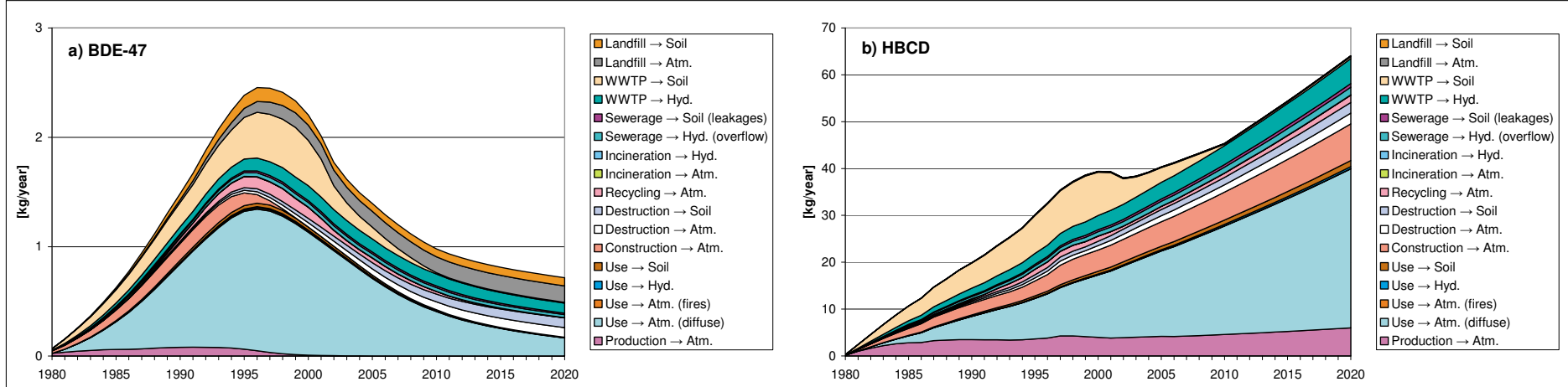

Fig. 5. Total emissions of (a) BDE-47 and (b) HBCD to the environment, subdivided by different emission sources

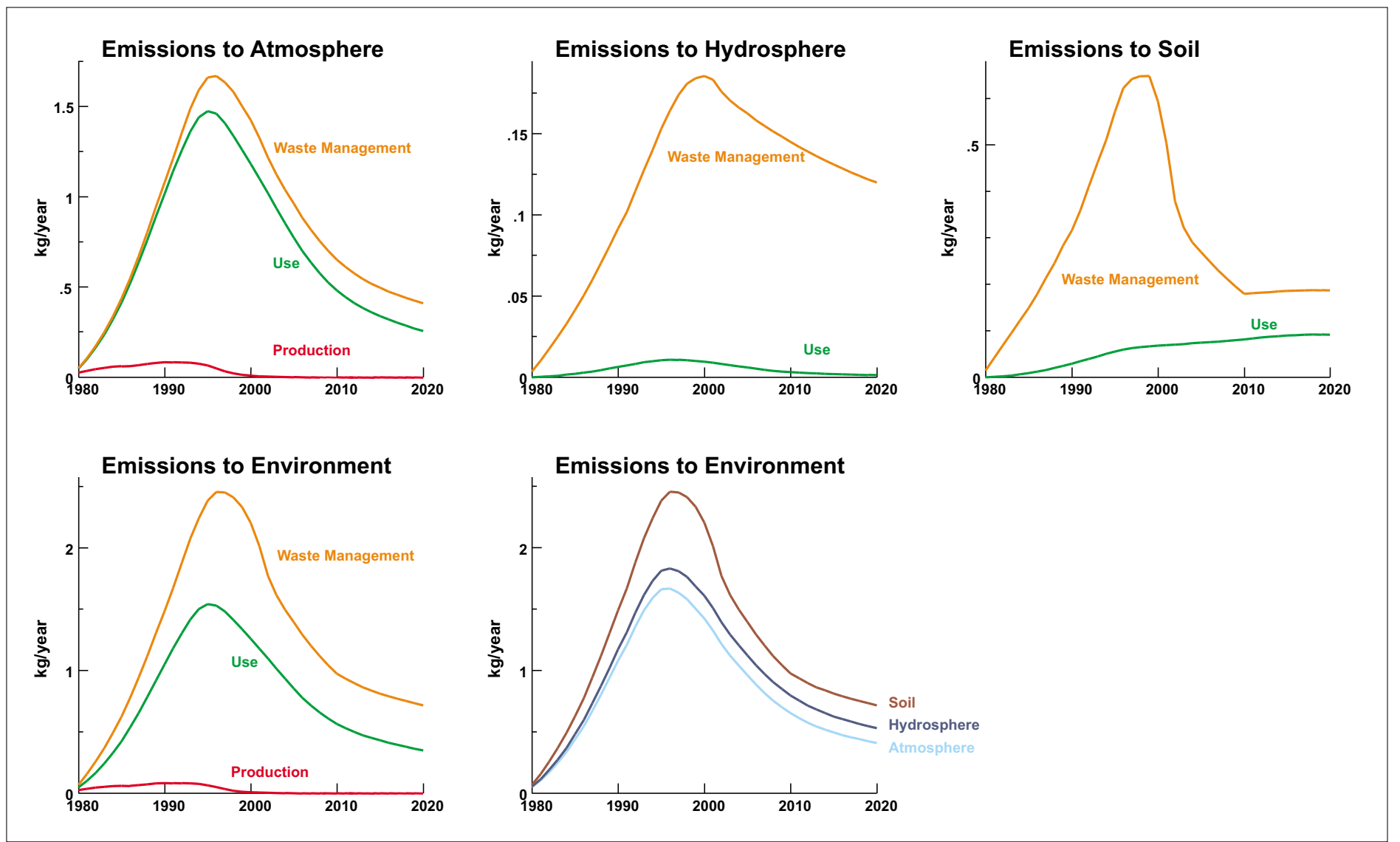

Fig. 6. Emissions of BDE-47 to atmosphere, hydrosphere, soil and environment, shown as cumulative graphs subdivided by source (bottom left) and by compartment (bottom centre)

the hydrosphere and soil are respectively 7 $\mathrm{kg} /$ year and $5 \mathrm{~kg} /$ year.

Construction materials are responsible for the majority of the emissions. Diffuse atmospheric emissions of HBCD from installed EPS and XPS insulation panels account for about half of the emissions. As the stock in the use phase has been growing over the whole period, these diffuse emissions will increase to $30 \mathrm{~kg} /$ year in 2020. Actual atmospheric emissions from the manufacturing of flame-retarded insulation panels ( $4 \mathrm{~kg} / \mathrm{year}$ ), as well as from construction and destruction operations $(8 \mathrm{~kg} /$ year), are also relevant. While emissions from destruction processes are simulated to increase further for a long period due to the growing flow from the use phase to the destruction process, emissions from the construction process are highly dependent on the mass of HBCD consumed in insulation materials in future. Therefore, only this component of total emissions could be influenced rapidly by regulatory measures. The application areas $E \& E$, transport and textiles/furniture were simulated to account for $9 \mathrm{~kg} /$ year $(23 \%$ of the total) at the end of the 1990s and $6 \mathrm{~kg} /$ year $(15 \%)$ at present. The most important emission source within these three application areas is diffuse emission during the use phase $(3 \mathrm{~kg} /$ year between the mid-1990s and 2020), particularly from vehicles and textiles.
The wastewater pathway, including in particular emissions due to the use of sewage sludge as fertiliser and emissions from WWTP effluents to the hydrosphere, produced HBCD emissions of $4 \mathrm{~kg} /$ year in the late 1990s and $2 \mathrm{~kg} / \mathrm{year}$ at present. Atmospheric emissions from automobile and electronic appliance recycling plants amounted to $1 \mathrm{~kg} / \mathrm{year}$ at the end of the 1990 s, while a $50 \%$ decrease is projected by 2020 . Because HBCD is not retained in sewage sludge as effectively as, for example, decaBDE (which has a higher $\mathrm{K}_{\mathrm{OW}}$ ), a larger fraction of the substance entering WWTPs is released as effluent. The sewage sludge used in agriculture led to emissions of $10 \mathrm{~kg} /$ year in 1999 , but today most 
of the sludge is incinerated, as a result of which emissions by this pathway have been reduced to about $2 \mathrm{~kg} /$ year at present. While emissions from the recycling of vehicles, insulation panels and E\&E were calculated to account for about $2 \%$ of the total, atmospheric HBCD emissions from the process incineration account for only $0.1 \%$, starting from the 1990s.

\section{Scenario Calculation}

As already mentioned above, the dynamic SFA is able to calculate scenarios, such as a ban or substitution of a chemical, improvement of air-pollution-control technology or changes in waste management strategy. The Table explains scenarios which were selected and simulated in the present study, and the main results of these simulations. Results for the influence of an unchanged waste management system are presented in Ref. [20].

\section{Conclusions}

The use of a dynamical substance flow model, combined with more reliable field data, evaluation of historical data and estimates of future developments, have allowed us to improve substantially the quality of the results obtained from a stationary substance flow model by Morf et al. in 2002.[16] The results from this kind of study provide specific and considerable improvements in the quality of information concerning the life cycle of chemicals compared to the information used in regular risk assessments. Indeed, it was possible not only to simulate emissions as a function of time but also to identify major anthropogenic source terms of chemicals over the period investigated. Because the selected BFRs include candidates (such as pentaBDE) to be added to the Stockholm Convention on Persistent Organic Pollutants, the results will be valuable in assessing risk-reduction action to be taken for POPs. The strategy of continuous introduction of advanced technology in waste management and of improvements in downstream user processes are found to be primarily responsible for a relative reduction of emissions in Switzerland over the past 20 years.

The study illustrates possibilities for reducing emissions and human exposure. As one example, in the event that action is required due to a negative EU risk assessment outcome for HBCD, the replacement of non-defective EPS and XPS insulation panels might be a waste of resources, and also be too expensive. Apart from using other insulation material or EPS and XPS with a substitute flame retardant (which has not been found yet), measures to reduce emission during renovation and destruction may be taken (such as refraining from breaking insulation panels on site).

Table. Different model scenario calculations and their consequences for emissions to the environment in Switzerland.

\section{Scenario \\ Major consequences due to measure}

\section{Ban on usage of chemical in 2007}

HBCD in construction materials

Further increase in emissions avoided, reduction of one third compared to reference scenario induced by 2020. However more than 50 years would be required to achieve a significant emissions reduction.

DecaBDE for all applications except E\&E

Decrease of total consumption by approximately $30 \%$.

Releases to wastewater reduced from 30 to approximately $24 \mathrm{~kg} /$ year in 2020 (-20\%).

Very little influence on use-phase stock level and almost no influence on landfill stock.

Emissions to environment reduced from 13 to $9 \mathrm{~kg} / \mathrm{year}$ by 2020 (-30\%).

DecaBDE for all applications

Consumption decrease to negligible amount because only a minor proportion of waste materials containing decaBDE is expected to be reused.

Releases to wastewater reduced from 24 to approximately $8 \mathrm{~kg} /$ year in 2020 (-67\%).

Influence on stock in use phase is much larger than if $E \& E$ were to be exempted from a ban. Instead of decrease to 1,600 tonnes by 2020 , stock is estimated as 550 tonnes for the same year. This difference is highly significant for diffuse emissions from use phase.

Emissions to environment in 2020 are simulated as $3 \mathrm{~kg} / \mathrm{year}$, a reduction factor of approximately 5 compared to reference scenario.

\section{Influence of invariant waste management system on emissions}

For decaBDE in application area of $E \& E$

Without the modern waste management system in effect in Switzerland since 1980 , emissions related to E\&E applications would be approximately $10 x$ higher today.

The most important pathways which were reduced are:

- atm. emissions from recycling (2 kg/year vs. $40 \mathrm{~kg} / \mathrm{year}$ )

- atm. emissions from incineration ( $0.2 \mathrm{~kg} / \mathrm{year} v \mathrm{~s} .20 \mathrm{~kg} /$ year)

- sewage sludge to soil (3 kg/year vs. $40 \mathrm{~kg} /$ year)

For decaBDE, short of a possible ban the most important regulatory measures already seem to have been taken in Switzerland (namely incineration of the sewage sludge, state-of-the-art techniques in municipal solid waste incineration plants and prohibition of the dumping of combustible waste). A reduction of emissions from electronic appliance and automobile recycling plants may also be beneficial. For a further reduction of emissions from the wastewater pathway, measures to diminish sewer leakage and overflows during heavy rain would lead to a reduction in the input of decaBDE (and other pollutants removed efficiently in WWTPs) to the hydrosphere and soil.

In order to be ready for further efficient risk-reduction measures, the following major data gaps were identified as needing additional investigation:

i) emission factors for automobile recycling plants, especially for shredding operations;

ii) long-term emission data for different product categories in the use phase under real conditions;

iii) fate data for BFR substances as soon as such chemicals are emitted from the original products (indoor emission pathways and distribution);

iv) measured data concerning release terms from electronic appliance or automobile recycling facilities to wastewater;

v) field data for HBCD concentrations in soil and realistic degradation half-lives;

vi) concentrations in agricultural, natural or even remote soils for HBCD.

For the future we recommend - in line with a major conclusion of the NRP50 consensus platform 'Brominated Flame Retardants' - efforts to further improve the knowledge of the lifecycle of chemicals such as the BFRs studied in this project. By applying SFA as a suitable tool to weight the effect of substance flows with respect to emissions to the environment, the results of such investigations serve as a rational basis for planning systematic action and measures to reduce the risk of such chemicals to humans and to the environment.

\section{Acknowledgements}

The project was funded by the Swiss National Science Foundation (Project FABRO, 4050-111389, National Research Programme 50). The authors would like to thank all their 
colleagues in other NRP50 projects for their cooperation, support with important information and critical questions (especially the group of M. Kohler at EMPA). Thanks are also due to other researchers and experts around the world who supported the investigation with important supplementary information (particularly S. I. Sakai and his group).

Received: March 22, 2008

[1] L. S. Birnbaum, D. F. Staskal, Environ Health Perspect. 2004, 112, 9.

[2] BSEF; Bromine Science and Environmental Forum, 2003, Vol. 2003.

[3] C. A. de Wit, M. Alaee, D. C. G. Muir, Chemosphere 2006, 64, 209.

[4] J. Legler, A. Brouwer, Environment International 2003, 29, 879.

[5] M. Trachsel, Consensus Platform 'Brominated Flame Retardants', Swiss National Research Foundation, 2007; M. Trachsel, Chimia 2008, 62, 432 .

[6] European Chemicals Bureau, 'Technical Guidance Document on Risk Assessment', 2003.

[7] European Chemicals Bureau, 'European Union Risk Assessment Report: pentabromo diphenyl ether', 2000.

[8] European Chemicals Bureau, 'European Union Risk Assessment Report: octabromo diphenyl ether', 2003.

[9] European Chemicals Bureau, 'European Union Risk Assessment Report: bis(pentabromophenyl) ether (Update)', 2004.

[10] C. Zeltner, H.-P. Bader, R. Scheidegger, P. Baccini, Regional Environmental Change 1999, 1,31 .

[11] T. Tasaki, T. Takasuga, M. Sako, S. I. Sakai, Waste Management 2004, 24, 571.
[12] S. Hashimoto, H. Tanikawa, Y. Moriguchi, Waste Management 2007, 27, 1725.

[13] M. Streicher, H.-P. Bader, R. Scheidegger, S. Kytzia, Clean. Techn. Environ. Policy 2007, 9, 325.

[14] I. Bjotveit, 'Bruken av bromerte flammehemmere i produkter - Materialstrømsanalyse', Norwegian Pollution Control Authority SFT, 2003.

[15] 'Brominated Flame Retardants: Substance Flow Analysis and Assessment of Alternatives', Danish Environmental Protection Agency, 1999.

[16] L. Morf, R. Taverna, H. Daxbeck, R. Smutny, 'Selected polybrominated flame retardants, PBDEs and TBBPA, Substance flow analysis', Buwal Swiss Federal Office for the Environement, 2002.

[17] A. Leisewitz, W. Schwarz, 'Flammhemmende Ausrüstung ausgewählter Produkte - anwendungsbezogene $\mathrm{Be}$ trachtung: Stand der Technik, Trend, Alternativen', 2001, UBA-Texte 26/01, Berlin.

[18] P. Baccini, H.-P. Bader, 'Regionaler Stoffhaushalt: Erfassung, Bewertung und Steuerung' Spektrum Akademischer Verlag, Heidelberg, 1996

[19] L. S. Morf, J. Tremp, R. Gloor, Y. Huber, M. Stengele, M. Zennegg, Environ. Sci. \& Technol. 2005, 39, 8691.

[20] L. S. Morf, A. M. Buser, R. Taverna, H.-P. Bader, R. Scheidegger, Waste Management \& Research $\mathbf{2 0 0 8}$, in preparation.

[21] A. M. Buser, L. S. Morf, R. Taverna, H.-P. Bader, R. Scheidegger, Chemophere 2008, in preparation.

[22] K. Prevedouros, K. C. Jones, A. J. Sweetman, Environ. Sci. \& Technol. 2004, $38,3224$. 